\title{
1005
}

\section{Estimation of Carbonate Elastic Properties Using Nanoindentation and Digital Images}

\author{
O. de Paula* (Curtin University), M. Pervukhina (CSIRO Petroleum), B. \\ Gurevich (Curtin University/CSIRO Petroleum), M. Lebedev (Curtin \\ University), M. Martyniuk (University of Western Australia) \& C. Delle \\ Piane (CSIRO Petroleum)
}

\section{SUMMARY}

Petrophysical properties of carbonate reservoirs are less predictable than the properties of silisiclastic reservoirs. The main reason for that is chemical interaction of carbonate rocks with percolating fluids, ion exchange and recrystallization in geological time. Quantification of the elastic variability of carbonate grains on the microscale is the first step to constrain models and to obtain more realistic predictions of practically important rock properties of carbonate reservoirs. In this study we present elastic moduli of an oolite sample from the Pleistocene Dampier Formation of Southern Carnarvon Basin, Western Australia obtained by the nanoindentation technique. Young moduli of this highly heterogeneous sample are measured at 49 points regularly distributed in a 70x70micrometer rectangular grid on the surface. The frequency diagram shows bimodal distribution of the Young moduli that correspond to dense calcite phase and rare (dissolved) calcite phase. These two solid phases are apparent in the high resolution scanning electron microscope images. We used the obtained moduli of the dense and rare phases for numerical modelling of elastic properties of the carbonate sample from micro-CT images. The results of the numerical modelling using finite element code are compared with the elastic moduli obtained from acoustic velocities measured by ultrasonic technique. 


\section{Introduction}

Carbonates rock physic properties are by far less predictable than those of silisiclastic reservoir rocks because of their chemical sensitivity to interstitial fluids and their variable porosity. Carbonates can become rapidly hard due the early diagenesis. Nevertheless, when they are exposed or in the contact with fresh water, a dissolution process is triggered increasing the macro and micro porosity and changing the elastic parameters of the weathered rock.

With the aim of better constraining the elastic properties of porous carbonates and the variability of elastic moduli at the microscale, we undertake a multidisciplinary study where results from microstructure visualization by the means of microCT (3D), electron microscopy (2D), and nanoindentation experiments are used to feed finite element models.

A sample of heavily weathered oolitic carbonate from the southern Carnarvon Basin, Western Australia is first analysed using the microCT technique to visualize the pore distribution and connectivity in 3D, subsequently SEM images are acquired from the same sample to image the microporosity and phases distribution. Nanoindentation tests are used to measure the elastic parameters of various regions of the samples more or less affected by dissolution. Using these results a finite element model simulating the elastic behaviour of the carbonate is finally fine tuned.

Results indicate that the local elastic properties of the oolitic rock are strongly dependent on its microporosity which in turn affects the bulk behaviour. Young's modulus variation is almost three fold from $144 \mathrm{GPa}$ in the micritic cement to $56 \mathrm{GPa}$ in the partly dissolved rims of the ooids.

Heterogeneities and dissolution patterns of the analysed oolite are present from the outcrop to the microscale, a detailed knowledge of the their influence on the bulk rock elastic and mechanical properties can help constraining realistic models and reduce the uncertainties related to exploration in carbonate reservoirs.

\section{Carbonate Sample and the Nanoindentation Experiment}

The nanoindentation experiment is performed in an oolite sample (Figure 1) from the Pleistocene Dampier Formation, Southern Carnarvon Basin, Western Australia. More details about the Pleistocene Dampier Formation and the oolite distribution can be found in Logan et al. (1970). The sample has a complex structure that was formed during several stages of deposition and diagenesis. Concentric calcite rings deposited around a quartz core can be clearly seen at an SEM image (Figure 2). The black round and irregular spots present secondary intragranular microporosity formed due to calcite dissolution in the concentric calcite rings, especially, outer ones. Macropores between oolite particles were also developed in the micritic cement during diagenesis (Figures 1 and 2).

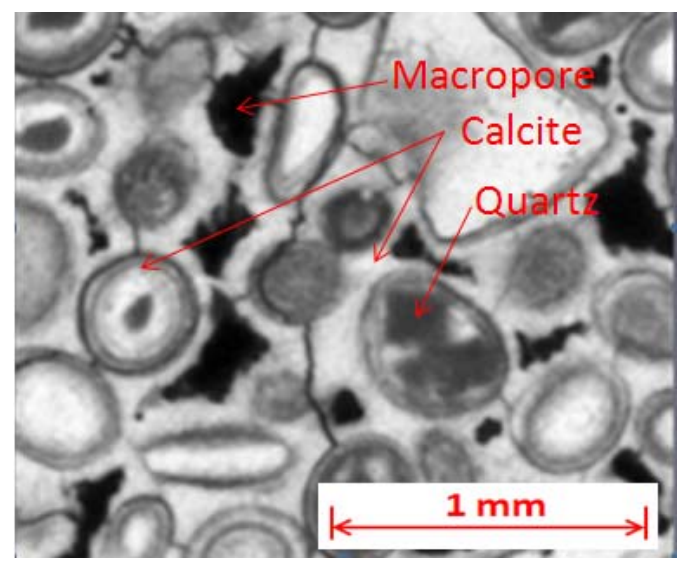

Figure 1 Oolite microCT image with details of microstructure complexity.

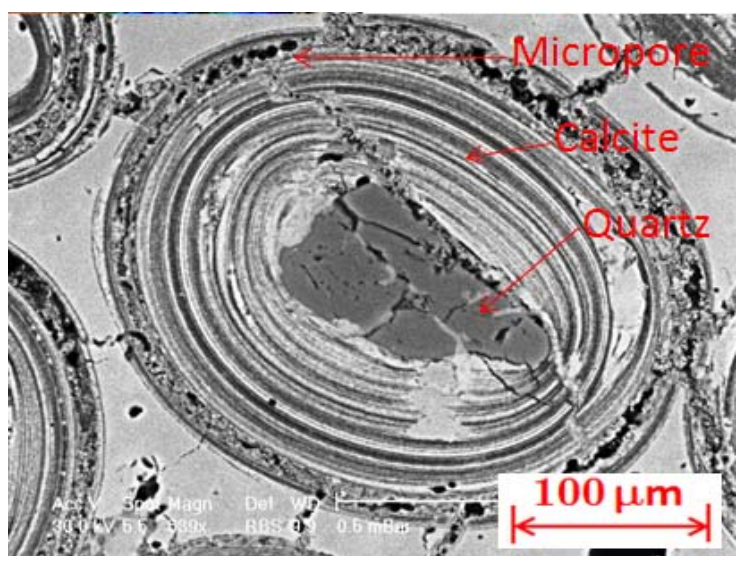

Figure 2 Oolite SEM image showing fractured quartz seed, calcite rings and macro/microporosity. 
At the preparation stage the oolite sample is polished and the residual topography is shown in atomic force microscope (AFM) image (Figure 3). Residual roughness of about $80 \mathrm{~nm}$ is resulted from different resistance to abrasion of the micritic cement and stiff concentric rings (beige colour) and softer rings (blue valleys). The AFM image (Figure 3) maps concentric ring pattern which is similar to micro-CT and SEM images what implies that different parts of this carbonate sample, i.e. dense and dissolved concentric calcite rings and micritic cement have different elastic properties which can be measured by nanoindentation technique.

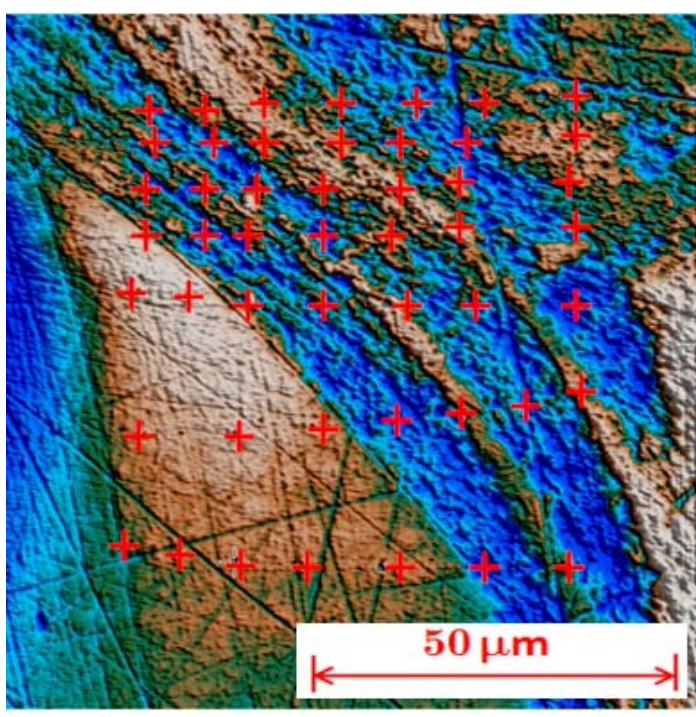

Figure 3 Oolite topographic map from -40 $\mathrm{nm}$ (blue) to $40 \mathrm{~nm}$ (white) after polishing and with the nanoindentation grid superimposed.

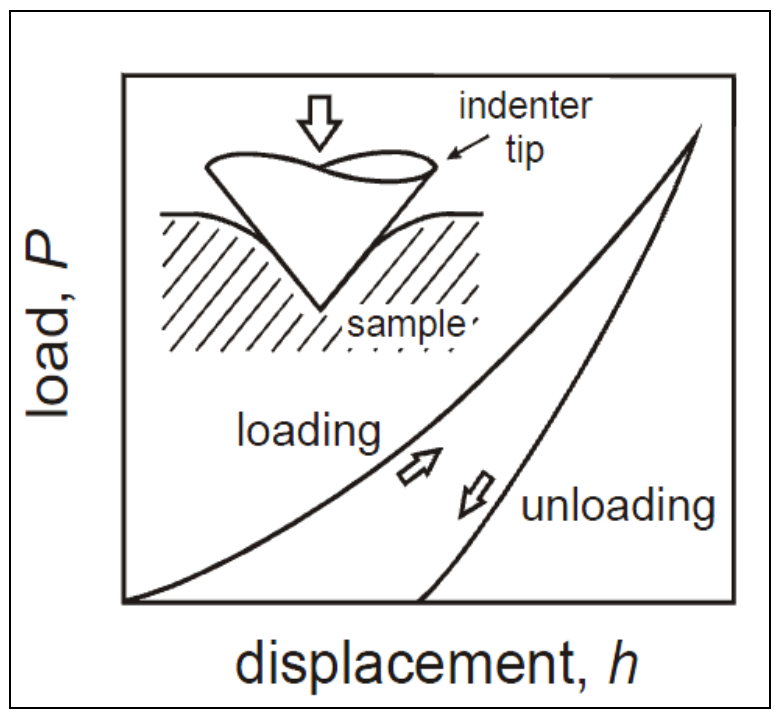

Figure 4 Indenter experiment with the penetration depth history into a test sample as a function of an applied load $P$ (from Martyniuk, 2006).

We used so-called grid-indentation technique as recently used by Ulm and co-workers for heterogeneous materials (Ortega et al., 2007). The technique is based on a number of nano-contact experiments and statistical analysis of resulting measurements. A total of 49 nano-contact points marked by red crosses in Figure 3 are distributed over a wide area which embraces dense and dissolved carbonate concentric rings of an oolite particle and micritic cement. Force-driven indentation tests are operated for each of the nano-contact points using Hysitron nanoindenter TS70. Young's moduli for each point are calculated from measured load $\mathrm{P}$ and indentation depth $\mathrm{h}$ (see Figure 4 for more details) as follows

$$
E=\frac{\sqrt{\pi}}{2} \frac{S}{\sqrt{A_{c}}}\left(1-v^{2}\right) .
$$

Here $v$ is Poisson ratio, $\mathrm{S}=(\mathrm{dP} / \mathrm{dh})_{\mathrm{h}=\mathrm{hmax}}$ is the unloading slope of the force-depth curve and $\mathrm{A}_{\mathrm{c}}$ is the projected contact surface between the indenter and the deformed material surface, which is determined as a function of the measured maximum indentation depth, $\mathrm{h}_{\max }$.

The histogram of the Young's moduli obtained from the experiment is shown in Figure 5. Two calcite components can be inferred on the basis of analysis of the histogram, i.e., the harder component with an average value of Young's modulus of about $144 \mathrm{GPa}$ and the softer component with Young's modulus of about $56 \mathrm{GPa}$. 


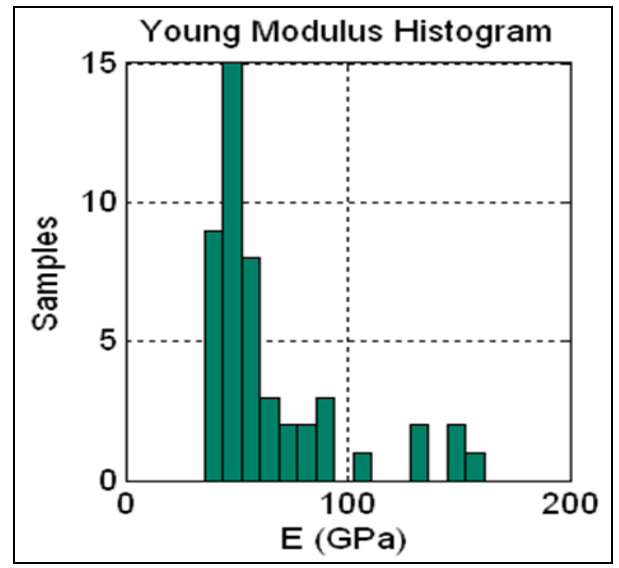

Figure 5 Distribution of calcite Young Modulus obtained for the indentation in an oolite sample (49 points).

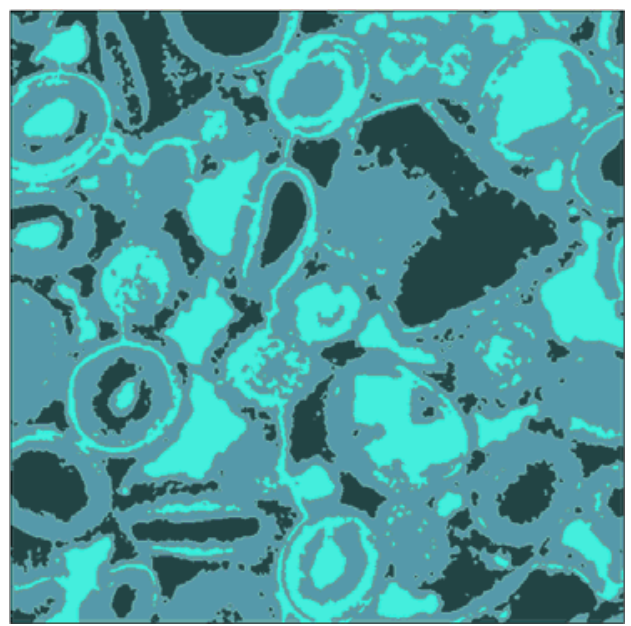

Figure 7 Oolite segmented CT_image showing 3 phases: pore space (blue), soft calcite (grey) and hard calcite (dark grey).

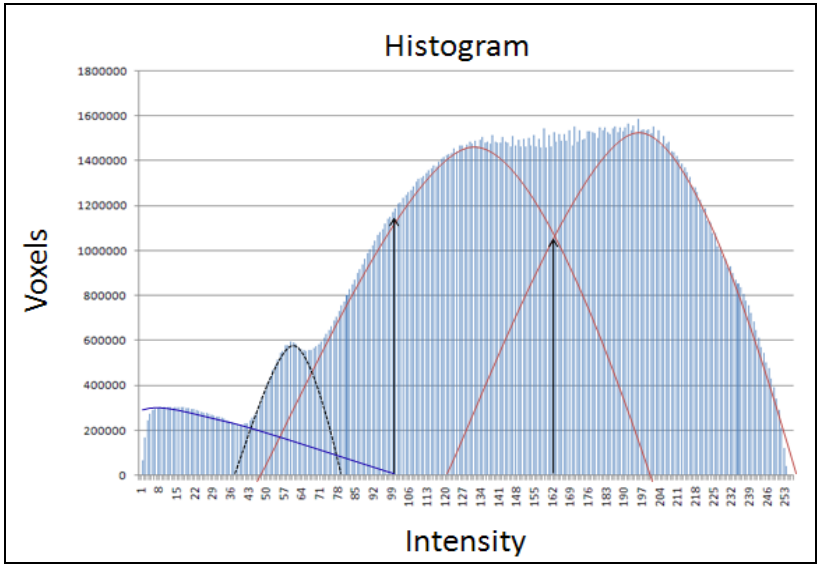

Figure 6 Histogram of the CT image showing the low intensity values due the pore space (blue), an intermediate cluster due to quartz (black) and the higher intensities due to soft and harder calcite (red).

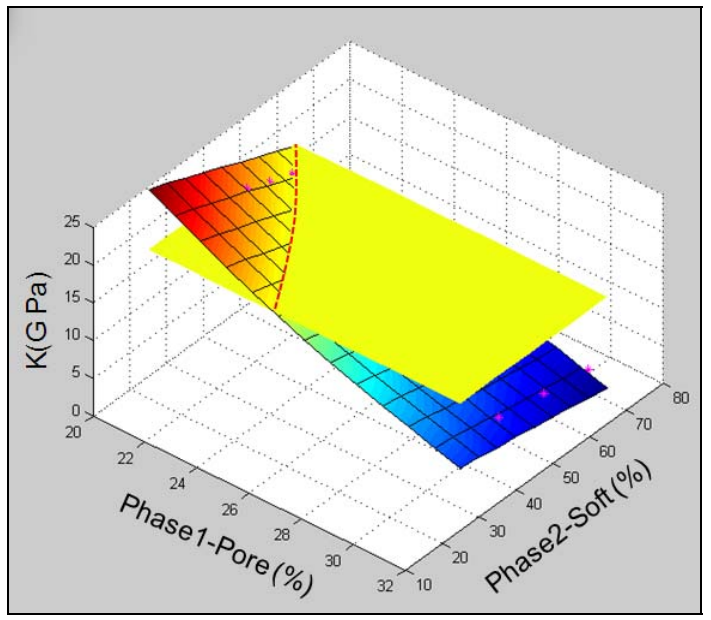

Figure 8 Bulk Modulus from modelling as a function of porosity and soft/hard calcite ratios. In yellow Bulk Modulus from ultrasonic measurements.

\section{Elastic Modelling}

The histogram of the gray-level distribution obtained from the microCT image of the oolite carbonate sample is shown in Figure 6. All four main phases, namely, stiff and soft calcite phases, quartz and pores can be distinguished at the histogram. The pore space (or extremely dissolved calcite) distribution is shown by blue envelope curve, quartz by black one and stiff and soft calcite are shown by red curves.

To obtain the effective elastic moduli from the microCT images we use a Finite Element Method (FEM). The FEM code (Arns, 2000) simulates an effective elastic moduli using as an input exact 3D geometry of each phase and its elastic moduli. In order to simplify the model and analyze the sensibility due only to different calcite phase ratios (soft and hard) we have segmented the images into three phases: porous space, soft and hard calcite (Figure 7). We generated nine distinct segmented 
images using AVIZO (VSG, Inc.) software, varying volumes of pore space (phase 1) from $21 \%$ to $31 \%$, soft calcite (phase 2) from $29 \%$ to $58 \%$ and hard calcite from $15 \%$ to $39 \%$.

Simulated elastic moduli are used to generate a surface of all possible solutions in 3D domain (Figure 8). The interception of the surface with the plane $\mathrm{K}=16.7 \mathrm{GPa}$ that represents the bulk modulus obtained by ultrasonic measurements (yellow surface in Figure 8) gives a line (in red) of all possible solutions constrained with experimental results. The surface of solutions (Figure 8) given by the FEM modelling can be used to show the carbonate evolution with time if we assume that the soft calcite emerged as a result of partial dissolution of the harder calcite phase.

\section{Conclusions}

Nanoindentation technique has been shown to be practically useful for measuring the elastic parameters of the mineral constituents of a complex oolitic carbonate sample. The results obtained from the nanoindentation technique allow separation of two calcite phases with Young's moduli of $144 \mathrm{GPa}$ and $56 \mathrm{GPa}$. These two phases can be also identified in microCT images due to different intensity values. Exact 3D distribution of the two calcite phases obtained from microCT images by segmentation has been used for simulation of elastic moduli of the carbonate sample. The simulated moduli are in a good agreement with the bulk and shear moduli of $16.7 \mathrm{GPa}$ and $8.2 \mathrm{GPa}$, respectively, obtained from experimental results.

\section{Acknowledgements}

We would like to thank Petrobras - Petroleo Brasileiro S.A. for the support in this work and Mark Knackstedt and Michael Turner from ANU for generating the microCT images .

\section{References}

Arns, C.H., Knackstedt, M.A., Pinczewski, W.V. and Garboczi, E.J. [2002] Computation of linear elastic properties from microtomographic images: Methodology and agreement between theory and experiment. Geophysics, 5:1396-1405.

Logan, B.W., Davies, G.R., Read, J.F., and Cebulski, D.E. [1970] Carbonate sedimentation and environments, Shark Bay, Western Australia. Memoir of the American Association of Petroleum Geologists, 13, 223.

Martyniuk, M. [2006] Low-Teperature Micro-Opto-Electro-Mechanical Technologies for temperature Sensitivive. PhD Thesis. The University of Western Australia.

Ortega, J.A., Ulm, F.J., Abousleiman, Y. [2007]. The effect of the nanogranular nature of shale on their poroelastic behavior. Acta Geotechnica. 2, 155-182.

Perez-Huerta,A., Cusack,M., Zhu,W., England,J. And Hughes,J. [2007] Material properties of brachiopod shell ultrastructure by nanoindentation. Jornal of Royal Society Interface, 4, 33-39.

Ulm, F. J. and Younane Abousleiman. [2006] The Nanogranular Nature of Shale. Acta Geotechnica, $1(2), 77-88$. 